\title{
Inhibition of acid-sensing ion channel 1a attenuates acid-induced activation of autophagy via a calcium signaling pathway in articular chondrocytes
}

\author{
WEN-FAN GAO ${ }^{1}$, YA-YUN XU ${ }^{1}$, JIN-FANG GE ${ }^{2}$ and FEI-HU CHEN ${ }^{2}$ \\ ${ }^{1}$ Department of Pharmacy, Anhui Mental Health Center, Hefei, Anhui 230000; \\ ${ }^{2}$ School of Pharmacy, Anhui Medical University, Hefei, Anhui 230032, P.R. China
}

Received July 14, 2018; Accepted January 30, 2019

DOI: $10.3892 / \mathrm{ijmm} .2019 .4085$

\begin{abstract}
Acid-sensing ion channel 1a (ASICla), member of the degenerin/epithelial sodium channel protein superfamily, serves a critical role in various physiological and pathological processes. The aim of the present study was to examine the role of ASICla in the autophagy of rat articular chondrocytes. Autophagy was induced by acidic stimulation in rat articular chondrocytes and the extent of autophagy was evaluated via the expression levels of microtubule-associated protein 1 light chain 3II, Beclin1 and uncoordinated-51 like kinase1. Suppression of ASICla was achieved using small interfering RNA technology and/or inhibitor psalmotoxin-1. The expression levels of autophagy markers were measured by western blot analysis and reverse transcription-quantitative polymerase chain reaction methods. Intracellular calcium $\left(\left[\mathrm{Ca}^{2+}\right]_{\mathrm{i}}\right)$ was analyzed using a $\mathrm{Ca}^{2+}$-imaging method. Additionally, protein expression levels of the $\mathrm{Ca}^{2+} /$ calmodulin-dependent protein kinase kinase $\beta(\mathrm{CaMKK} \beta) / 5$ '-monophosphate-activated protein kinase (AMPK)/mammalian target of rapamycin (mTOR) pathway were measured by western blot analysis. The results showed that autophagy was increased in a $\mathrm{pH}$ - and time-dependent manner with exposure to an acidic environment. In addition, silencing ASICla significantly decreased the expression levels of autophagy makers, accompanied by abrogation of the acid-induced $\left[\mathrm{Ca}^{2+}\right]_{\mathrm{i}}$ increase.
\end{abstract}

Correspondence to: Professor Fei-Hu Chen, School of Pharmacy, Anhui Medical University, 81 Mei-Shan Road, Hefei, Anhui 230032, P.R. China

E-mail: cfhchina@sohu.com

Abbreviations: LC3, microtubule-associated protein 1 light chain 3; $\mathrm{AO}$, acridine orange; ULK1, uncoordinated-51 like kinase 1; CaMKK $\beta$, $\mathrm{Ca}^{2+} /$ calmodulin-dependent protein kinase kinase $\beta$; AMPK, 5'-monophosphate-activated protein kinase; mTOR, mammalian target of rapamycin

Key words: acid-sensing ion channel 1a, rat, articular chondrocyte, autophagy, $\mathrm{Ca}^{2+}$
Furthermore, silencing of ASIC1a downregulated the levels of CaMKK $\beta / \beta$-actin and phosphorylated (p-) AMPK/AMPK, and upregulated the levels of $\mathrm{p}$-mTOR/mTOR. These results indicated that ASICla is a potent regulator of autophagy in chondrocytes, which may be associated with decreased $\mathrm{Ca}^{2+}$ influx and the CaMKK $\beta / A M P K / m T O R$ pathway.

\section{Introduction}

Rheumatoid arthritis (RA) is an inflammatory disease characterized by intra-articular decreases in $\mathrm{pH}$, aberrant hyaluronan regulation and destruction of bone and cartilage (1). It has been reported that the severity of pain and joint damage correlates with the degree of acidity in the synovial fluid from arthritic joints (2). Due to the fact that chondrocytes, the only cell type present in articular cartilage, are important in the pathogenesis of arthritis and are profoundly affected by local $\mathrm{pH}$ (3), articular chondrocytes were selected to examine the pathogenesis of RA in vitro in the present study.

The acid-sensing ion channel (ASIC) is a member of the degenerin $/ \mathrm{Na}^{+}$channel superfamily, and is an insensitive cation channel activated by extracellular protons (4). The ASIC family in mammals includes four genes, encoding seven subtypes, in which ASICla is the only subunit for the transport of $\mathrm{Ca}^{2+}(5-7)$. In addition to the role of synaptic plasticity, the activation and sensitization of ASICla is involved in acidosis-induced ischemic brain damage caused by $\mathrm{Ca}^{2+}$ influx in neurons (8). Our previous studies have shown that ASICla is involved in the injury of articular chondrocytes caused by increased intracellular calcium $\left(\left[\mathrm{Ca}^{2+}\right]_{\mathrm{i}}\right)$ induced by acidosis $(9,10)$. Furthermore, the inhibition of ASICla was reported to confer a protective effect on articular cartilage in adjuvant arthritis rats (10). Therefore, in the present study, the role of ASICla in the acid-induced activation of articular chondrocyte autophagy was further investigated.

Autophagy, a cellular self-digestion process, is an essential, conserved, lysosomal degradation pathway that controls the quality of the cytoplasm by eliminating protein aggregates and damaged organelles (11). Low levels of autophagic activity are commonly observed under normal conditions, presumably preserving normal cellular homeostasis (12). In addition to its vital homeostatic role, this degradation pathway 
is involved in various human disorders, including metabolic disease, neurodegenerative diseases, cancer and inflammatory diseases (13-16). It has been reported that autophagy can be induced by different extracellular or intracellular stress and signals, including nutrient depletion, hypoxia, growth factor deprivation, endoplasmic reticulum (ER) stress, the accumulation of unfolded proteins, heat shock and microbial infection (17). A previous study indicated that autophagy may protect cells from acidosis-induced cell damage (18). In addition, autophagy was reported to be activated in osteoarthritis models (19). However, whether autophagy can be induced by acidic stimulation in rat articular chondrocytes in vitro remains to be fully elucidated. Three autophagy-related proteins, microtubule-associated protein 1 light chain 3II (LC3II), uncoordinated-51 like kinase 1 (ULK1) and Beclin1, were selected as markers of the extent of autophagy in the present study. Additionally, it has been identified that influx of $\mathrm{Ca}^{2+}$ is closely associated with autophagy (20). The activation of $\mathrm{Ca}^{2+}$-permeable ASICla was shown to be responsible for acidosis-mediated ischemic brain injury caused by $\mathrm{Ca}^{2+}$ influx in neurons (7). Based on these findings, the present study aimed to investigate whether the inhibition of ASICla was involved in the activation of autophagy through influencing $\mathrm{Ca}^{2+}$ influx.

Mammalian target of rapamycin (mTOR) is a serine/threonine protein kinase that regulates cell growth, proliferation, motility, survival, protein synthesis and transcription. Substantial evidence indicates that mTOR functions as a negative regulator of autophagy (21). In addition, rapamycin, an mTOR inhibitor, has been shown to increase autophagy in several cell types, including chondrocytes (22-24). Previous studies have indicated that the calcium/calmodulin-dependent protein kinases, a family of serine/threonine kinases responsive to intracellular $\mathrm{Ca}^{2+}$ concentration, may have regulatory roles in autophagy. CaMKK $\beta$, an important member of the family, may function as an upstream kinase for adenosine 5'-monophosphate (AMP)-activated protein kinase (AMPK) and regulate autophagy in response to elevations in cytosolic calcium through B-cell lymphoma 2 (25). It has been shown that AMPK, by inducing tuberous sclerosis complex 1/2-Rheb inhibition of mTOR, is also important in chondrocyte autophagy $(26,27)$. Considering the aforementioned results, these proteins may be involved in acid-induced autophagy.

In the present study, in order to examine the potential effect of ASICla on acid-induced autophagy and the related underlying mechanisms, inhibition of ASICla was achieved using small interfering (si) RNA technology or the inhibitor psalmotoxin-1 (PcTX1). The expression levels of autophagy markers, including LC3II, ULK1 and Beclin1, were evaluated using western blot analysis and reverse transcription-quantitative polymerase chain reaction (RT-qPCR) analysis. In addition, intracellular calcium $\left(\left[\mathrm{Ca}^{2+}\right]_{\mathrm{i}}\right)$ was analyzed using a $\mathrm{Ca}^{2+}$-imaging method. The protein expression levels of CaMKK $\beta$, AMPK and mTOR were also observed by western blot analysis.

\section{Materials and methods}

Cell isolation and culture. A total of 10 male, 2-month-old Sprague-Dawley (SD) rats (160-180 g) were purchased from Anhui Experimental Animal Center of China [animal license no. SYXK (Wan) 2012-006]. They were housed five per cage (43 cm long x $31 \mathrm{~cm}$ wide x $19 \mathrm{~cm}$ high) with access to food and water ad libitum, and maintained under a 12:12 h light/dark cycle. The ambient temperature was maintained at $21-22^{\circ} \mathrm{C}$ with $50-60 \%$ relative humidity. All experiments performed on animals were approved by the Animal Ethics Committee and complied with the Principles of Laboratory Animal Use and Care of Animal Ethics Committee of Anhui Medical University (Hefei, China; LLSC20140039).

Rat articular cartilage chondrocytes were obtained from the SD rats as described previously (28). Cartilage from the knee joint was cut into small sections $\left(\sim 1 \mathrm{~mm}^{3}\right)$ and initially digested with $0.2 \%$ collagenase type II (Sigma-Aldrich; Merck KGaA, Darmstadt, Germany) in phosphate-buffered saline (PBS). Following digestion, the cells were centrifuged at $323 \mathrm{x}$ g for $15 \mathrm{~min}$ at $4^{\circ} \mathrm{C}$ and washed three times with PBS. The freshly isolated chondrocytes were plated at $2 \times 10^{4}$ cells/well in plastic dishes filled with culture medium [Dulbecco's modified Eagle's medium (DMEM), supplemented with $2 \mathrm{mM}$ glutamine, $100 \mathrm{IU} / \mathrm{ml}$ penicillin, $100 \mathrm{mg} / \mathrm{ml}$ streptomycin and $10 \%$ fetal calf serum]. The cultures were maintained under sterile conditions at $37^{\circ} \mathrm{C}$ in a humidified air atmosphere with $5 \% \mathrm{CO}_{2}$ for up to 5 days.

Antibodies and reagents. Psalmotoxin-1 (PcTX1) was obtained from Alomone Labs, Ltd. (Jerusalem, Israel). BAPTA-AM was obtained from Dojindo Molecular Technologies, Inc. (Kumamoto, Japan). AMPK (cat. no. bsm-33447R), phosphorylated (p-) AMPK (cat. no. bs-3027R) and CaMKK $\beta$ (cat. no. bs-6253R) antibodies were obtained from Biosynthesis Biotechnology Co., Ltd. (Beijing, China). mTOR (cat. no. sc-1550-R), p-mTOR (cat. no. sc-293133) and $\beta$-actin (cat. no. sc-517582) antibodies were obtained from Santa Cruz Biotechnology, Inc. (Santa Cruz, CA, USA). ASIC1a (cat. no. SAB2108751) antibody was obtained from EMD Millipore (Billerica, MA, USA). Lipofectamine 2000 and TRIzol reagent were purchased from Invitrogen Life Technologies; Thermo Fisher Scientific, Inc. (Waltham, MA, USA). DMEM, fetal calf serum, and Opti-MEM were purchased from Gibco; Thermo Fisher Scientific, Inc.

siRNA-mediated suppression of ASICla. siRNA was utilized to suppress ASICla. The following phosphorylated oligonucleotides were used: ASIC1a (rat), forward 5'-CCCUUCAAC AUGCGUGAAUTT-3' and reverse 5'-AUUCACGCAUGU UGAAGGGTT-3'; negative control, forward 5'-UUCUCC GAACGUGUCACGUTT-3' and reverse 5'-ACGUGACAC GUUCGGAGAATT-3'. The expression levels were verified by RT-qPCR and western blot analyses.

Acridine orange (AO) staining. Acidic vesicles (autophagolysosomes) were visualized by supravital staining with AO ( $1 \mathrm{mM}$; Sigma; Merck KGaA). At the indicated time points, cells mounted on microscope slides were washed with PBS and placed in a trough with $\mathrm{AO}$ working solution $(2 \mu \mathrm{g} / \mathrm{ml})$. Following staining at $37^{\circ} \mathrm{C}$ for $15 \mathrm{~min}$, the dishes were washed gently with PBS and then examined under an inverted fluorescent microscope (Olympus IX 83; Olympus Corporation, Tokyo, Japan) with an emission wavelength of $405 \mathrm{~nm}$. Depending on their acidity, the autophagolysosomes appeared as orange/red fluorescent cytoplasmic vesicles, whereas nuclei 
Table I. Primers of liver fibrosis-related gene amplified by reverse transcription-polymerase chain reaction.

\begin{tabular}{llc}
\hline Primer & \multicolumn{1}{c}{ Primer sequence } & Product length (bp) \\
\hline ASIC1a & F: 5'-GGACACACAGATGGCTGATGAAA-3' & 333 \\
& R: 5'-GTCTCTCCCCACACAGGCAAATA-3' & 146 \\
Beclin1 & F: 5'-CGTGGAGAAAGGCAAGATTGAAGA-3' \\
& R: 5'-GTGAGGACACCCAAGCAAGACC-3' \\
ULK1 & F: 5'-CCCAGCAACATCCGAGTCAAGA-3' \\
& R: 5'-CAGGTCAGCCTTCCCATCGTAGT-3' & 147 \\
GAPDH & F: 5'-CAACGGGAAACCCATCACCA-3' & 96 \\
& R: 5'-ACGCCAGTAGACTCCACGACAT-3'
\end{tabular}

ASIC1a, acid-sensing ion channel 1a; ULK1, uncoordinated-51 like kinase 1; F, forward; R, reverse.

were stained green. The accumulation of acidic vesicles was quantified as the red/green fluorescence ratio.

$\left[\mathrm{Ca}^{2+}\right]_{i}$ measurements. Intracellular $\mathrm{Ca}^{2+}$ imaging was performed as previously described (29). The cells were washed three times with D-Hank's solution and incubated with $4 \mu \mathrm{m}$ Fluo-3-AM and 0.02\% Pluronic F-127 (Biotium, Inc., Fremont, $\mathrm{CA}$, USA) for $30 \mathrm{~min}$ at $37^{\circ} \mathrm{C}$. Following incubation, the cells were washed three times with Hank's solution at $25^{\circ} \mathrm{C}$ to remove the extracellular Fluo-3-AM. The cells were then perfused, initially with D-Hank's solution and PcTX1 and then with buffer containing acid ( $\mathrm{pH}$ 6.0). In order to eliminate the effects of voltage-gated $\mathrm{Ca}^{2+}$ channels and $\mathrm{Ca}^{2+}$ release from intracellular stores, nimodipine $(5 \mu \mathrm{M})$, $\mathrm{x}$-conotoxin MVIIC $(3 \mu \mathrm{M})$ and $1 \mu \mathrm{M}$ thapsigargin were added to the extracellular fluid. The fluorescence of intracellular FLU-3 was quantified by confocal laser scanning fluorescence microscopy with an excitation wavelength of $488 \mathrm{~nm}$ and an emission wavelength of $525 \mathrm{~nm}$.

Quantitation of GFP-LC3-positive cells. The rat articular chondrocytes were seeded at a density of $3 \times 10^{5}$ cells/well into a 6-well plate overnight. Subsequently, the GFP-LC3 plasmid (5 $\mu \mathrm{l}$ ) was transfected into cells with $5 \mu \mathrm{l}$ Lipofectamine 2000 according to the manufacturer's protocol. At $24 \mathrm{~h}$ post-transfection, the cells were stimulated with acid for $3 \mathrm{~h}$ at $37^{\circ} \mathrm{C}$, following which the cells were placed in DMEM supplemented with $10 \%$ fetal calf serum and incubated for $4 \mathrm{~h}$. The chondrocytes were transfected with the GFP-LC3 plasmid and positive cells expressed a green florescent punctate pattern, which indicated autophagosome formation. Micrographs were captured on an Olympus confocal laser scanning microscope (Olympus Corporation) and the percentage of fluorescent cells was assessed.

RT-qPCR analysis. Total RNA was prepared using TRIzol reagent and evaluated by a One Drop OD-1000 spectrophotometer (Nanjing Wuyi Technology Co., Ltd., Nanjing, China). The primers were designed and synthesized by Invitrogen (Thermo Fisher Scientific, Inc.), according to the serial number from GenBank (Table I). Total RNA (500 ng) was reverse transcribed using a first-strand cDNA kit (Fermentas; Thermo Fisher Scientific, Inc.) into cDNA, according to the manufacturer's protocol and analyzed via qPCR using a SYBR-Green PCR
Master Mix (Takara Biotechnology Co., Ltd., Dalian, China) on a Step One platform (Applied Biosystems; Thermo Fisher Scientific, Inc.). qPCR was performed in a $25 \mu 1$ volume for 35 cycles $\left(40 \mathrm{sec}\right.$ at $95^{\circ} \mathrm{C}$; $30 \mathrm{sec}$ at $54^{\circ} \mathrm{C}$; and $30 \mathrm{sec}$ at $72^{\circ} \mathrm{C}$ ). GAPDH was used as an internal control for all samples. The relative amount of the target gene was calculated using the $2^{-\Delta \Delta \mathrm{Cq}}$ method (30).

Western blot analysis. The cells were washed twice with ice-cold PBS and lysed in buffer for 20-30 min on ice. The protein concentration was measured using the Bradford assay. Equal quantities of protein lysates $(\sim 50 \mu \mathrm{g})$ were separated on $10 \%$ SDS polyacrylamide gels and electrophoretically transferred onto polyvinylidene fluoride membranes. The membrane was blocked with $5 \%$ skim milk for $1 \mathrm{~h}$ at room temperature. The blots were probed with the appropriate primary antibodies (ASIC1a, Beclin1, LC3, mTOR, p-mTOR, AMPKa1, p-AMPKa1, CaMKK $\beta$ and $\beta$-actin; all 1:1,000) overnight at $4^{\circ} \mathrm{C}$, followed by incubation with horseradish peroxidase-conjugated rabbit anti-mouse (1:10,000; cat. no. ZB-2301; OriGene Technologies, Inc., Beijing, China) or goat anti-rabbit IgG (1:10,000; cat. no. ZB-2301; OriGene Technologies, Inc.) at $37^{\circ} \mathrm{C}$ for $2 \mathrm{~h}$. The results were visualized using an ECL assay kit (Pierce; Thermo Fisher Scientific, Inc.). Autoradiographs were scanned using Image-Pro Plus 6.0 Imaging analysis software (Media Cybernetics, Inc., Rockville, MD, USA).

Statistical analysis. Data are expressed as the mean \pm standard deviation. Statistical analyses were performed using SPSS 16.0 software (SPSS, Inc., Chicago, IL, USA). Comparisons among different treatment groups were conducted using one-way analysis of variance followed by LSD post hoc tests. $\mathrm{P}<0.05$ was considered to indicate a statistically significant difference.

\section{Results}

Rat articular chondrocyte observation and identification. Primary rat articular chondrocytes were round or polygonal in shape (Fig. 1A). Following $24 \mathrm{~h}$ of culture, the majority of cells exhibited adherent growth and long cytoplasmic shuttle translucent shapes (Fig. 1B). Following $72 \mathrm{~h}$ of cultivation, the majority of cells were adherently extended to form protrusions 
A

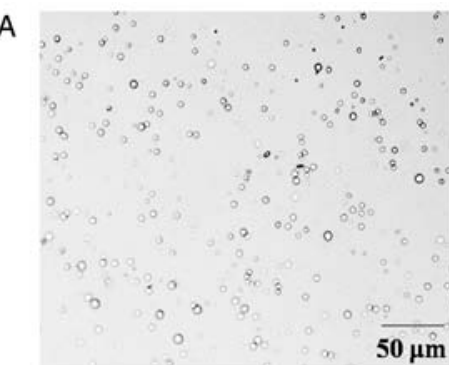

C

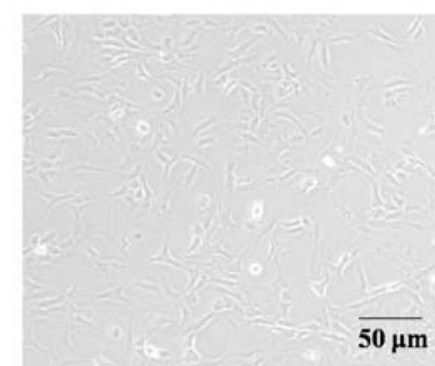

B

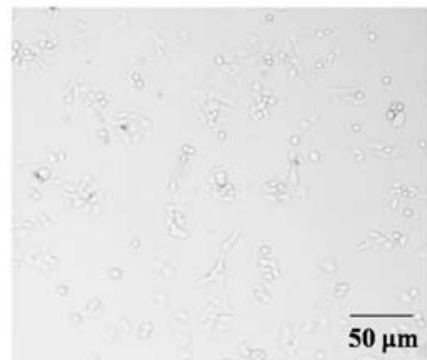

D

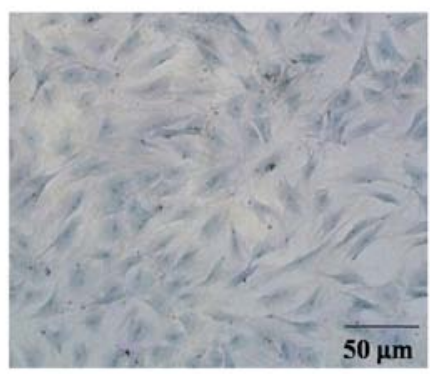

Figure 1. Morphological observation and identification of articular chondrocytes. (A) Morphology of primary articular chondrocytes at $0 \mathrm{~h}$. (B) Morphological of primary articular chondrocytes after $24 \mathrm{~h}$. (C) Morphology of primary articular chondrocytes after $72 \mathrm{~h}$. (D) Results of toluidine blue staining in articular chondrocytes .

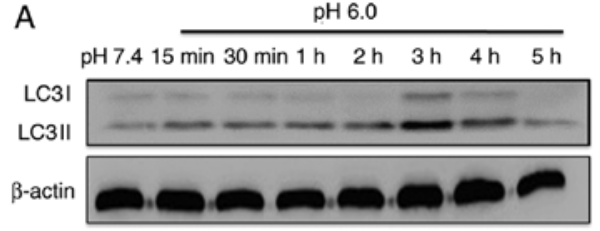

B
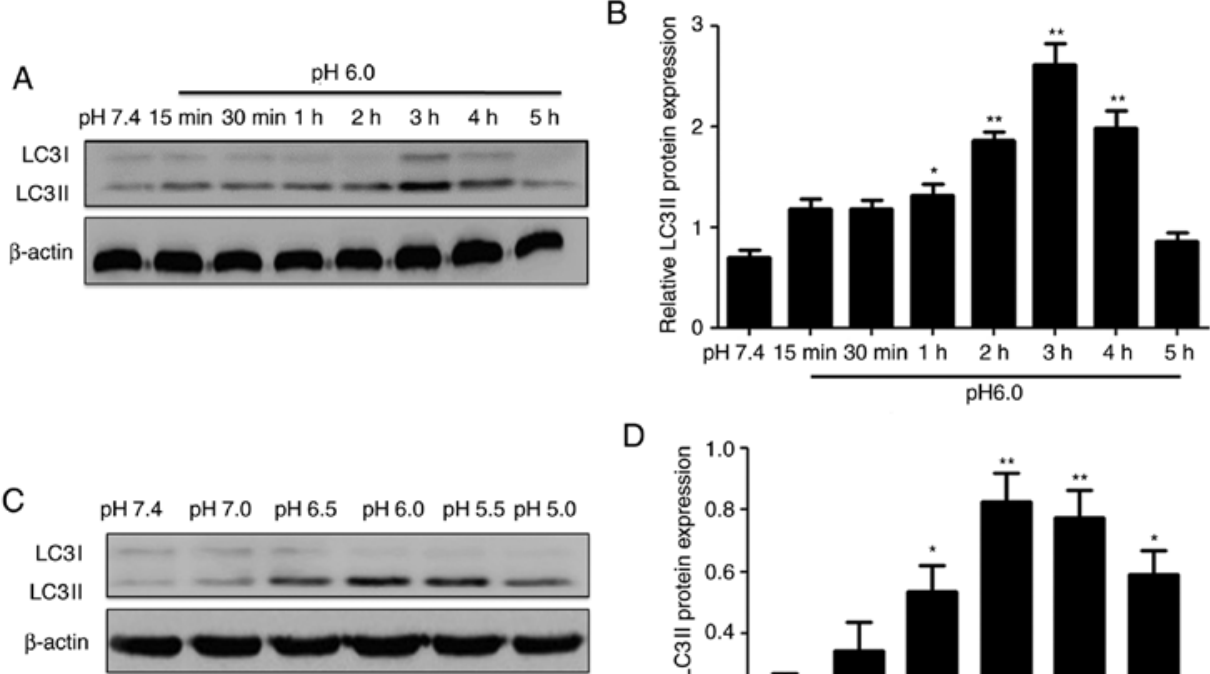

D

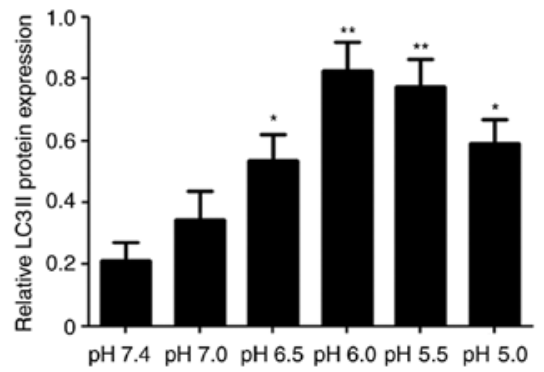

Figure 2. Effect of extracellular acidic solutions at different $\mathrm{pH}$ levels and for different time periods on the protein expression of LC3II in rat articular chondrocytes. Chondrocytes were treated without or with acid ( $\mathrm{pH} 6.0)$ for different time periods $(0-5 \mathrm{~h})$ and the results (A) visualized and (B) quantified. Chondrocytes were treated without or with acid at different $\mathrm{pH}$ levels and the results (C) visualized and (D) quantified. The results indicated that acidic treatment had a time- and pH-dependent effect on the expression of LC3II. ${ }^{*} \mathrm{P}<0.05$ and $^{* *} \mathrm{P}<0.01$, vs. $\mathrm{pH} 7.4$ group. LC3, microtubule-associated protein 1 light chain 3.

and joined into clusters (Fig. 1C). The cells were treated with toluidine blue, and the results showed that the nuclei were stained dark blue, whereas the cartilage cytoplasm and extracellular matrix were fuchsia on account of their metachromatic property. In addition, the cells exhibited a spindle shape and paving stone-like arrangement (Fig. 1D). These results demonstrated that the isolated cells were chondrocytes.

Extracellular acidification induces articular chondrocyte autophagy. To investigate whether autophagy occurred in response to extracellular acidification in the rat articular chondrocytes, the cells were treated with acidic stimulation for various $\mathrm{pH}$ and time periods. The protein expression of LC3II was selected to represent the level of autophagy. The results showed that extracellular acidification evidently increased the protein levels of LC3II in a time-dependent $(0-5 \mathrm{~h}$; Fig. 2A and B) and pH-dependent (pH 7.4-5.0; Fig. 2C and D) manner. These data suggested that acidic stimulation significantly upregulated the expression of LC3II in chondrocytes, indicating that extracellular acidification induced autophagy in rat articular chondrocytes.

ASICla inhibition suppresses acid-induced autophagy. As shown in Fig. 3A-C, extracellular acidification significantly 

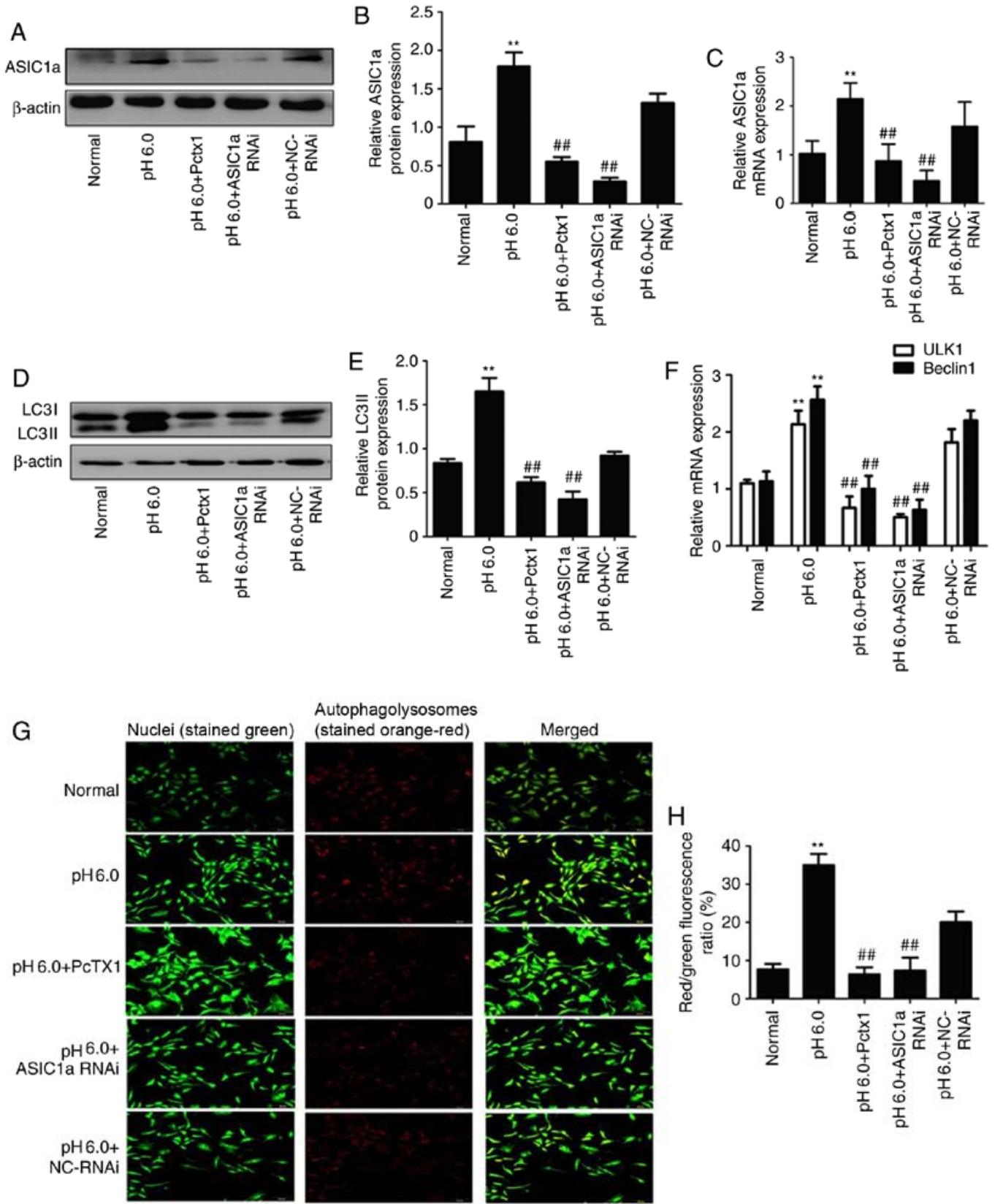

Autophagolysosomes
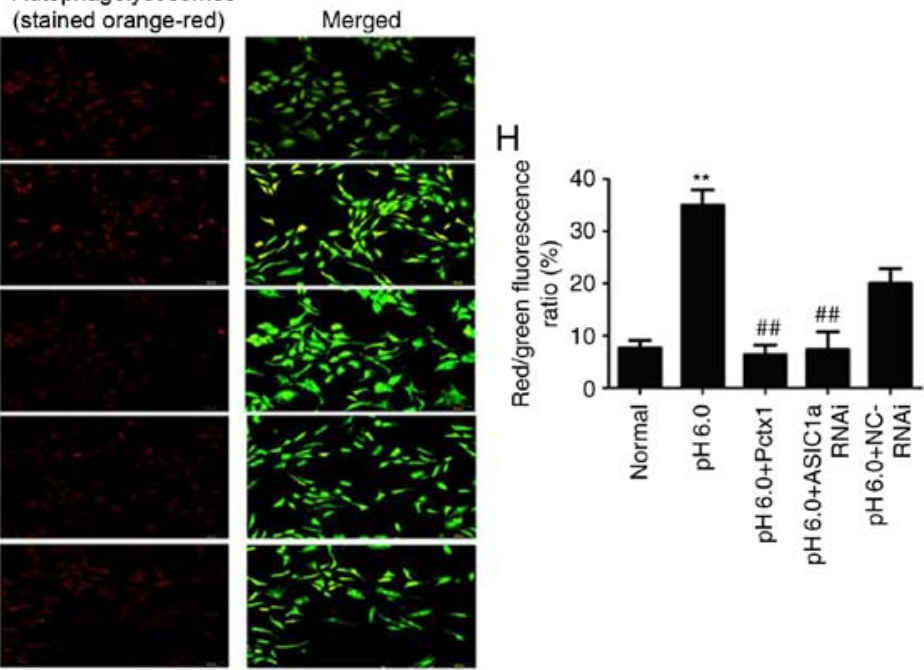

Figure 3. Effect of PcTX1 and small interfering RNA technology on the expression of ASICla and the activation of autophagy in rat articular chondrocytes. (A) Typical western blot image of the protein expression of ASIC1a. (B) Statistical results of the protein expression of ASIC1a. (C) Statistical results of the mRNA expression of ASIC1a. (D) Typical western blot image of the protein expression of LC3II. (E) Statistical results of the protein expression of LC3II. (F) Statistical results of the mRNA expression of Beclin1 and ULK1. (G) Articular chondrocytes were stained with acridine orange (magnification, x200). Left panels, nuclei (stained green); middle panels, autophagolysosomes (stained orange-red); and right panels, merged. (H) Statistical results of acridine orange. Fluorescent microscopy demonstrated an increase in red fluorescence in acid-treated chondrocytes, indicating the presence of extracellular acidification as a marker of autophagy. ${ }^{* *} \mathrm{P}<0.01$, vs. normal group; ${ }^{* \#} \mathrm{P}<0.05$, vs. $\mathrm{pH} 6.0$ group. ASICla, acid-sensing ion channel 1a; PcTX1, psalmotoxin-1; LC3, microtubule-associated protein 1 light chain 3; ULK1, uncoordinated-51 like kinase 1; RNAi, RNA interference; NC, negative control.

increased the protein levels of ASIC1a, whereas PcTX1 and ASIC1a RNA interference (RNAi) reversed the promoting effect of extracellular acidification on the protein (Fig. 3A and B) and mRNA (Fig. 3C) expression levels of ASICla in the articular chondrocytes.

The results in Fig. 3D-F show the effect of PcTX1 and ASICla RNAi on the protein and mRNA expression levels of autophagy markers, including LC3II (Fig. 3D and E), Beclin1 (Fig. 3F) and ULK1 (Fig. 3F). Compared with those in the normal group, the protein and mRNA expression levels of autophagy markers LC3II, Beclin1 and ULK1 were upregulated in the pH 6.0 group. However, these changes were decreased in the PcTX1 and ASICla RNAi groups, indicating that the inhibition of ASICla suppressed acid-induced autophagy.

In addition, the state of autophagy was examined by AO staining (Fig. 3G). The results revealed that the autophagolysosomes appeared as orange/red fluorescent cytoplasmic vesicles, whereas the nuclei were stained green. The $\mathrm{pH} 6.0$ group indicated a significant increase in greenish-yellow fluorescence when compared with the normal group, and the inhibition or silencing of ASICla by PcTX1 or siRNA technology resulted in a decrease in punctate fluorescence (Fig. $3 \mathrm{H}$ ). 
A Before acidification Acidification stimulation After acidification
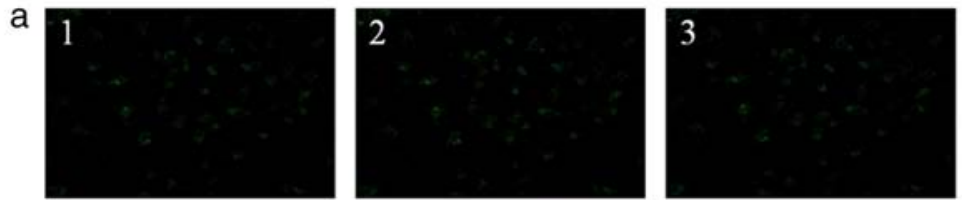

b
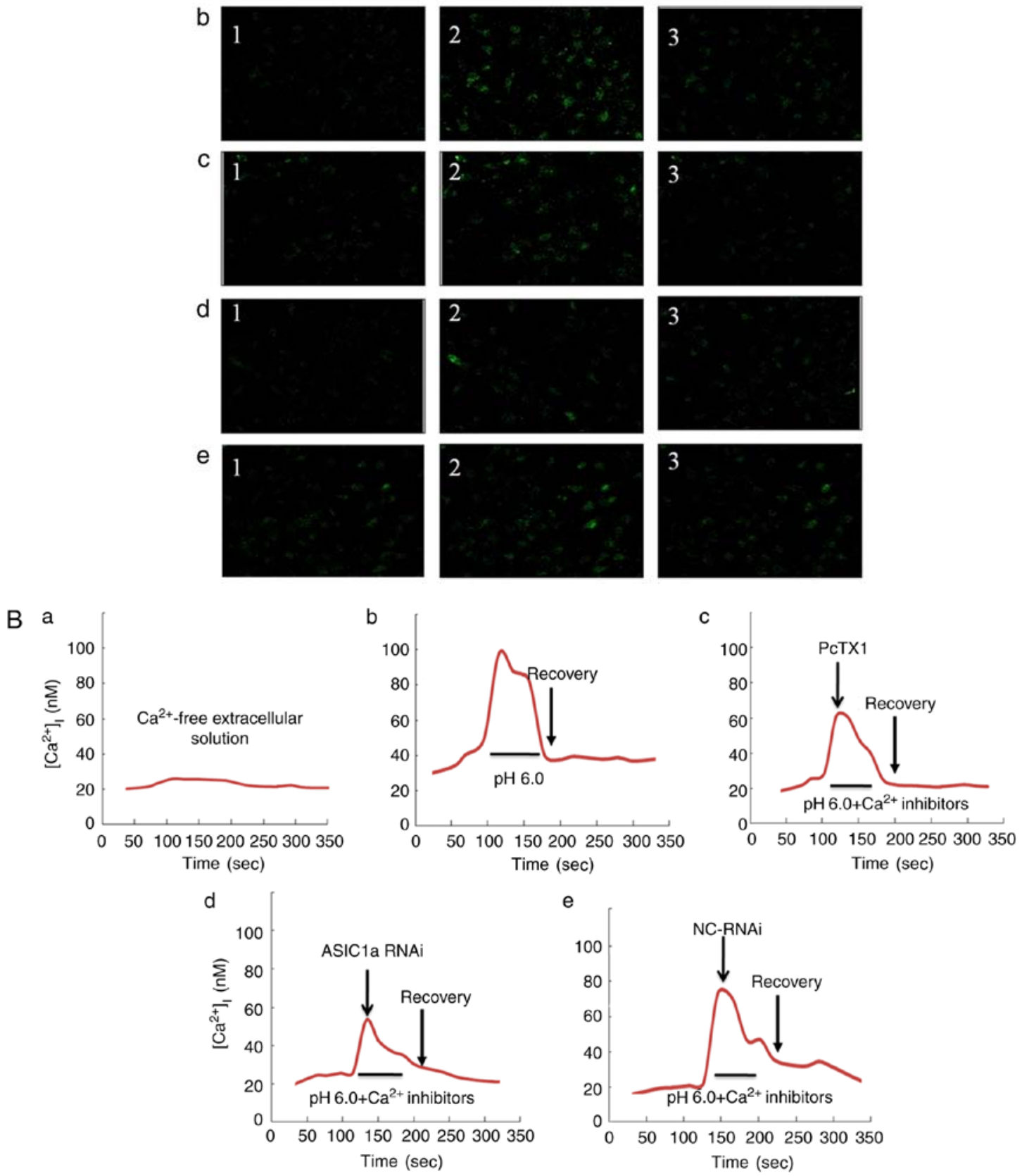

Figure 4. Knockdown of ASICla and PcTX1 reduces intracellular $\left[\mathrm{Ca}^{2+}\right]_{\mathrm{i}}$ in acid-mediated articular chondrocytes. (A) Cellular confocal micrographs showing changes in $\left[\mathrm{Ca}^{2+}\right]_{\mathrm{i}}$ concentration, as visualized by Fluo-3-AM in chondrocytes (magnification, $\mathrm{x} 200$ ); (a) acid-induced elevation of $\left[\mathrm{Ca}^{2+}\right]_{\mathrm{i}}$ in $\mathrm{Ca}^{2+}-\mathrm{free}_{\mathrm{S}}$ extracellular solution; (b) acid-induced elevation of $\left[\mathrm{Ca}^{2+}\right]_{\mathrm{i}}$ in extracellular $\mathrm{Ca}^{2+}$ solution; (c) acid-induced elevation of $\left[\mathrm{Ca}^{2+}\right]_{i}$ in chondrocytes treated with PcTX1; (d) acid-induced elevation of $\left[\mathrm{Ca}^{2+}\right]_{i}$ in chondrocytes treated with ASICla-specific RNAi; (e) acid-induced elevation of $\left[\mathrm{Ca}^{2+}\right]_{\mathrm{i}}$ in chondrocytes treated with NC-RNAi. (B) Intracellular $\mathrm{Ca}^{2+}$ imaging; (a) acid-induced elevation of $\left[\mathrm{Ca}^{2+}\right]_{\mathrm{i}}$ in $\mathrm{Ca}^{2+}$-free extracellular solution; (b) acid-induced elevation of $\left[\mathrm{Ca}^{2+}\right]_{\mathrm{i}}$ in extracellular $\mathrm{Ca}^{2+}$ solution; (c) acid-induced elevation of $\left[\mathrm{Ca}^{2+}\right]_{\mathrm{i}}$ in chondrocytes treated with PcTX1; (d) acid-induced elevation of $\left[\mathrm{Ca}^{2+}\right]_{\mathrm{i}}$ in chondrocytes treated with ASICla-specific RNAi; (e) acid-induced elevation of $\left[\mathrm{Ca}^{2+}\right]_{\mathrm{i}}$ in chondrocytes treated with NC-RNAi. ASIC1a, acid-sensing ion channel 1a; PcTX1, psalmotoxin-1; RNAi, RNA interference; NC, negative control.

Knockdown of ASICla downregulates intracellular $\left[\mathrm{Ca}^{2+}\right]_{i}$ in chondrocytes incubated in an acidic environment. Changes in $\left[\mathrm{Ca}^{2+}\right]_{\mathrm{i}}$ were investigated in the articular chondrocytes incubated in an acidic environment. In all experiments,
$10 \mu \mathrm{M}$ MK801, $5 \mu \mathrm{M}$ nimodipine, $3 \mu \mathrm{M}$ x-conotoxin MVIIC and $1 \mu \mathrm{M}$ thapsigargin were added to inhibit the possible secondary activation of glutamate receptors and voltage-gated $\mathrm{Ca}^{2+}$ channels and release of internal $\mathrm{Ca}^{2+}$ stores. As shown 
A

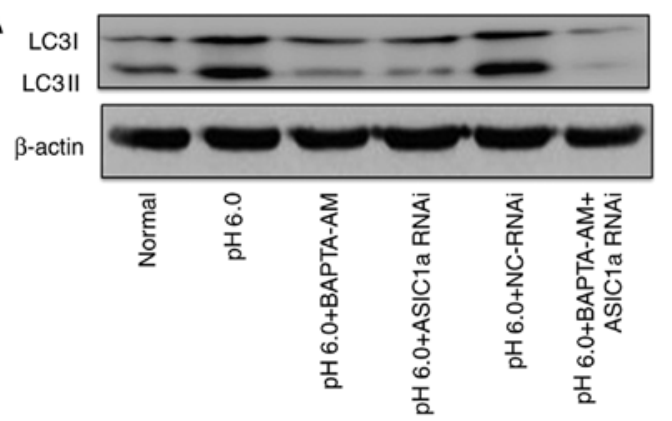

B

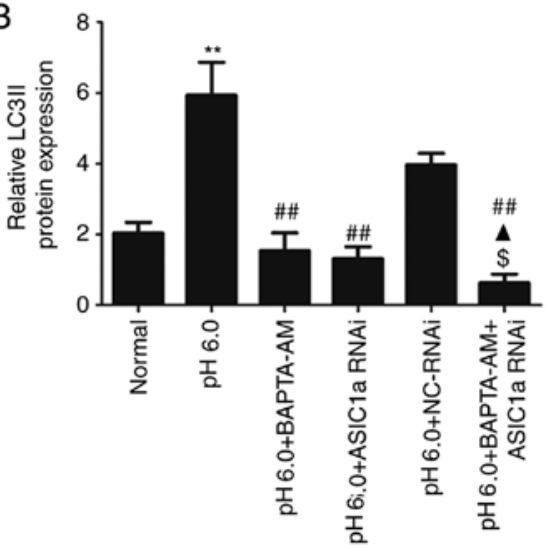

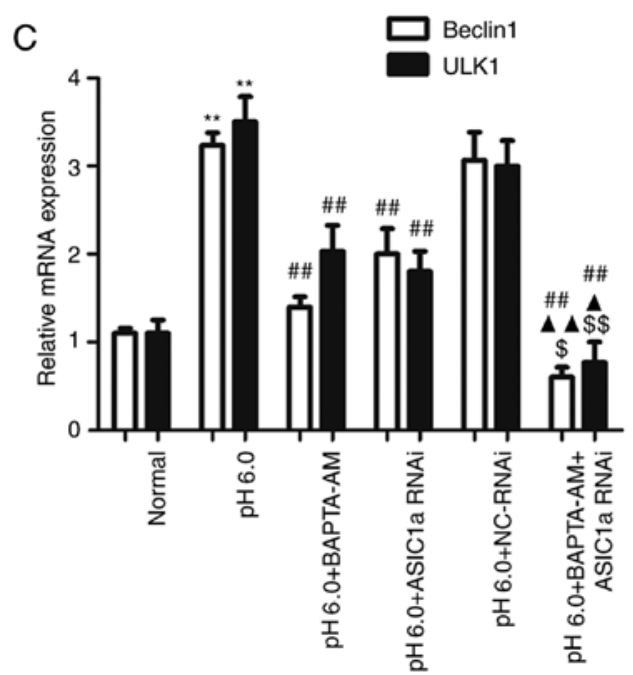

Figure 5. Effect of $\mathrm{Ca}^{2+}$ chelation on the protein and gene expression of autophagy markers. (A) Typical western blot image of the protein expression levels of LC3II. (B) Statistical results of the protein expression of LC3II. (C) Statistical results of the mRNA expression of Beclin1 and ULK1. **P $<0.01$, vs. normal group; ${ }^{\# \#} \mathrm{P}<0.05$, vs. pH 6.0 group; ${ }^{\$} \mathrm{P}<0.01$ and ${ }^{\$ \$} \mathrm{P}<0.05$, vs. pH $6.0+$ BAPTA-AM group; ${ }^{\wedge} \mathrm{P}<0.01$ and $\Delta \mathbf{\Delta} \mathrm{P}<0.05$, vs. pH $6.0+$ ASIC1a RNAi group. ASIC1a, acid-sensing ion channel 1a; LC3, microtubule-associated protein 1 light chain 3; ULK1, uncoordinated-51 like kinase 1; RNAi, RNA interference; $\mathrm{NC}$, negative control.

in Fig. 4Aa-e and Ba-e, $\left[\mathrm{Ca}^{2+}\right]_{i}$ was significantly elevated following the application of extracellular acidification ( $\mathrm{pH}$ 6.0) to articular chondrocytes (Fig. 4Ba-e). However, silencing or inhibiting ASICla reduced the intracellular $\mathrm{Ca}^{2+}$ concentration (Fig. 4A and B).

$\mathrm{Ca}^{2+}$ chelation inhibits acid-induced autophagy. As indicated in Fig. 5A and B, compared with extracellular acidification (pH 6.0), buffering the intracellular $\mathrm{Ca}^{2+}$ with cell-permeable chelator BAPTA-AM eliminated the acid-induced increase in the protein expression of LC3II. In addition, the levels of LC3II in cells pretreated with siRNA against ASICla in combination with BAPTA-AM were significantly lower compared with those in the cells with BAPTA-AM or ASICla silencing alone. The mRNA expression levels of Beclin1 and ULK1 (Fig. 5C) followed the same trend as LC3II. The chondrocytes with subsequently transfected with the GFP-LC3 plasmid. The results showed that cells treated with acidic stimulation exhibited an increase in fluorescent puncta, whereas the numbers of fluorescent puncta decreased in the BAPTA-AM and siRNA ASICla groups. The combined treatment resulted in a lower number of LC3-positive fluorescent puncta (Fig. 5C). These results were consistent with the protein and gene expression results, indicating that ASIC1a and intracellular $\mathrm{Ca}^{2+}$ are required for activation of the autophagic pathway in articular chondrocytes, and that ASICla and elevated intracellular $\mathrm{Ca}^{2+}$ levels may simultaneously serve critical roles in the regulation of acid-induced autophagy.

CaMKKR/AMPK/mTOR pathway is involved in acid-induced activated articular chondrocyte autophagy. As shown in Fig. 6, compared with the normal group, increased protein levels of CaMKK $\beta / \beta$-actin (Fig. $6 \mathrm{~A}$ and B) and p-AMPK/AMPK (Fig. 6C and D) were observed in the $\mathrm{pH} 6.0$ group. By contrast, the protein levels of p-mTOR/mTOR (Fig. 6E and F) were lower than those in the normal group. These changes were reversed in the BAPTA-AM and ASICla-siRNA groups. Following combined treatment, the protein levels of CaMKK $\beta / \beta$-actin and p-AMPK/AMPK were decreased further, whereas the protein levels of $\mathrm{p}$-mTOR/mTOR were increased further.

Simplified schematic representation of the inhibition of ASICla-mediated signaling pathways in autophagy. As shown in Fig. 7, the inhibition of ASICla attenuated the activation of autophagy via elevated intracellular calcium levels and the CaMKK//AMPK/mTOR signaling pathway. 
A

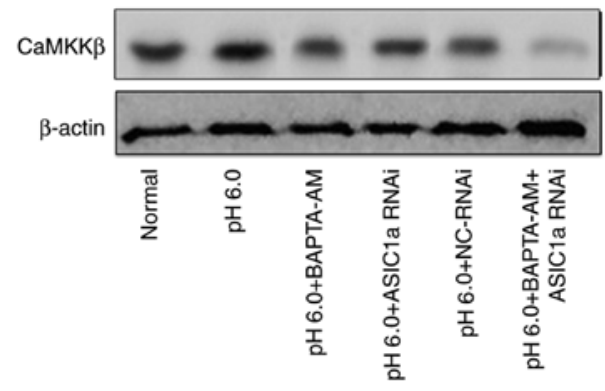

C

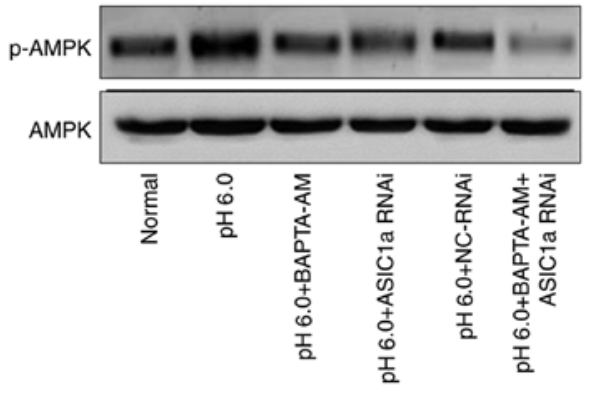

$E$

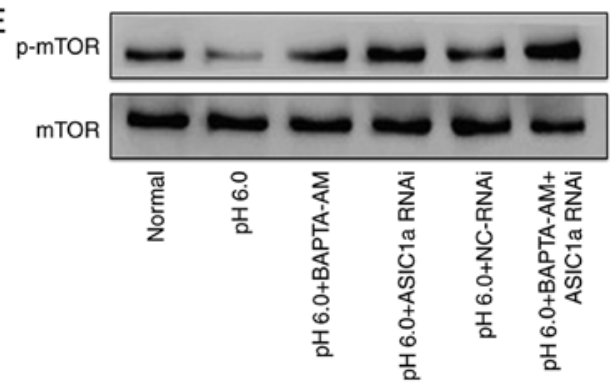

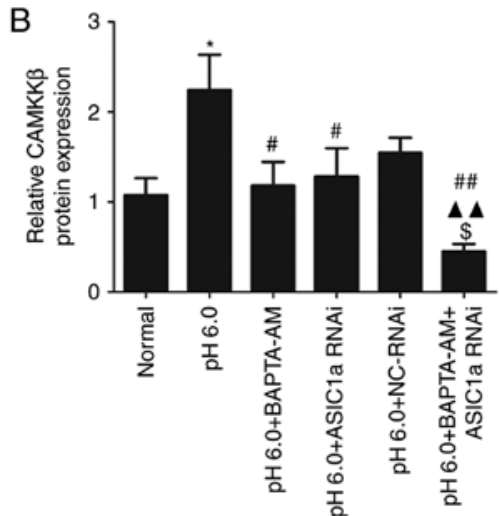
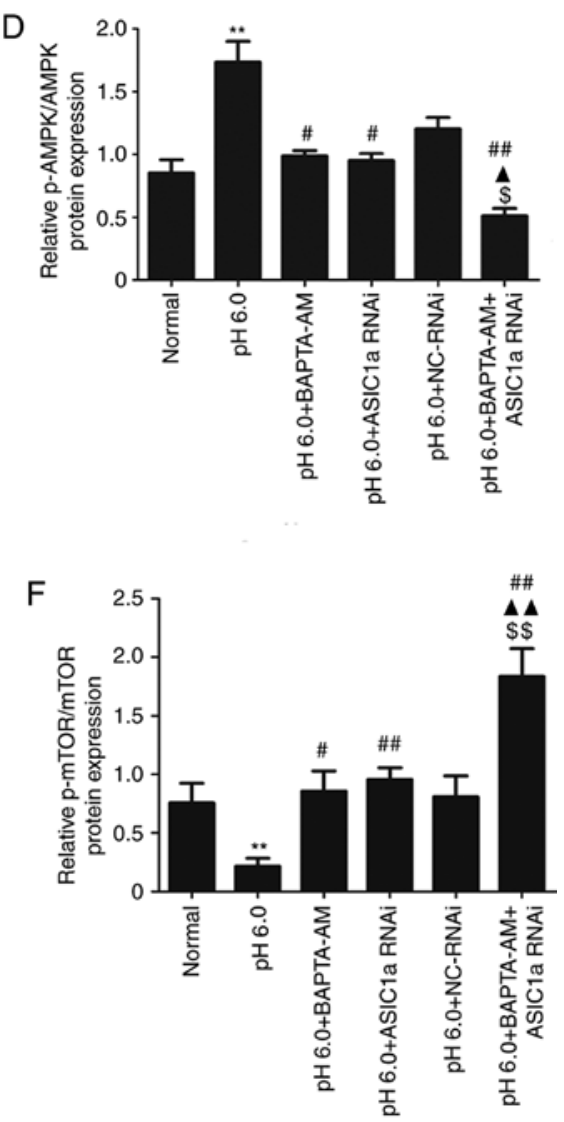

Figure 6. Effects of silencing the gene expression of ASIC1a on acid-dependent activation of the CaMKK $\beta / A M P K / m T O R$ pathway. (A) Typical western blot image of the protein expression levels of CaMKK $\beta$. (B) Statistical results of the protein expression of CaMKK $\beta$. (C) Typical western blot image of the protein levels of p-AMPK/AMPK. (D) Statistical results of the protein levels of p-AMPK/AMPK. (E) Typical western blot image of the protein levels of p-mTOR/mTOR. (F) Statistical results of the protein levels of p-mTOR/mTOR. " $\mathrm{P}<0.05$ and ${ }^{* *} \mathrm{P}<0.01$, vs. normal group, ${ }^{\#} \mathrm{P}<0.05$ and ${ }^{\# \#} \mathrm{P}<0.01$, vs. pH 6.0 group; ${ }^{\mathrm{S}} \mathrm{P}<0.01$ and ${ }^{\mathrm{SS}} \mathrm{P}<0.05$, vs. $\mathrm{pH} 6.0+\mathrm{BAPTA}-\mathrm{AM}$ group; ${ }^{\boldsymbol{\Lambda}} \mathrm{P}<0.01$ and ${ }^{\boldsymbol{\Lambda}} \mathrm{P}<0.05$, vs. $\mathrm{pH} 6.0+$ ASICla RNAi group. ASICla, acid-sensing ion channel 1a; CaMKK $\beta, \mathrm{Ca}^{2+} /$ calmodulin-dependent protein kinase kinase $\beta$; AMPK, 5'-monophosphate-activated protein kinase; mTOR, mammalian target of rapamycin; p-, phosphorylated; RNAi, RNA interference; NC, negative control.

\section{Discussion}

In the present study, it was demonstrated that extracellular acidification induced the activation of autophagy in a $\mathrm{pH}$ and time-dependent manner in rat articular cartilage. Based on these results, together with the fact that the inhibition of ASICla had a protective effect on articular cartilage, the role of ASICla in the acid-induced activation of autophagy was examined. The results showed that inhibition of ASICla attenuated the activation of autophagy via elevated intracellular calcium levels and the CaMKK $\beta /$ AMPK/mTOR signaling pathway.
Chondrocytes, the only cell type present in articular cartilage, have limited vascularity and exist in a low oxygen microenvironment. They are critical in maintaining the dynamic equilibrium between the synthesis and degradation of the extracellular matrix. It has been reported that chondrocyte metabolism is predominantly by anaerobic glycolysis, which produces a large quantities of lactate molecules, rendering the $\mathrm{pH}$ of the synovial tissue more acidic than the majority of other tissues (31). As pH in the majority of pathological conditions, including RA, tends to be $\sim 5.5$ (32), $\mathrm{pH}$ values of 7.0-5.0 were selected to mimic the extracellular acidification of RA in the 


\section{RA inflammation}

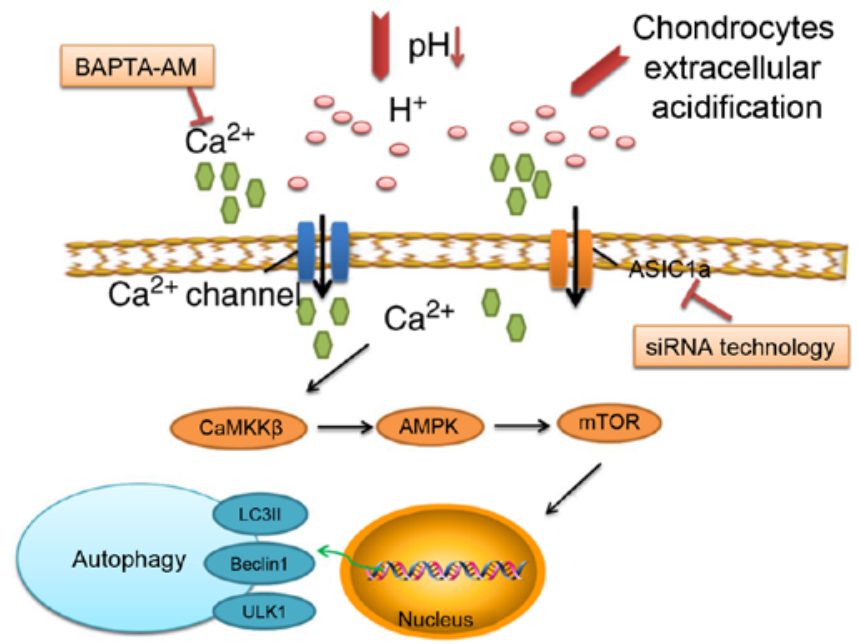

Figure 7. Schematic of the mechanism by which ASICla attenuates the activation of autophagy via elevated intracellular calcium levels and the CaMKK $\beta / A M P K / m T O R$ signaling pathway. RA, rheumatoid arthritis; siRNA, small interfering RNA; ASIC1a, acid-sensing ion channel 1a; $\mathrm{CaMKK} \beta, \mathrm{Ca}^{2+} / \mathrm{calmodulin}$-dependent protein kinase kinase $\beta$; AMPK 5 '-monophosphate-activated protein kinase; mTOR, mammalian targe of rapamycin; LC3II, microtubule-associated protein 1 light chain $3 \mathrm{II}$; ULK1, uncoordinated-51 like kinase 1.

present study. Based on the result that $\mathrm{pH} 6.0$ induced the maximal level of autophagy, as indicated by the expression of LC3II, the $\mathrm{pH}$ value of 6.0 was used to examined the effect of the inhibition of ASCS1a in autophagy in the subsequent experiments.

Autophagy is a lysosomal degradation mechanism that maintains cell homeostasis by transferring cell membranes into lysosomes in double vesicles termed autophagosomes (33). Basal levels of autophagy maintain intracellular homeostasis by removing damaged or toxic intrinsic components (34). Autophagy is stimulated under conditions of cellular stress. Under these conditions, the recycling of its own material provides a cell with building blocks that can be incorporated into newly synthesized macromolecules for cellular anti-stress responses and energy production to ensure survival. Autophagy is involved in various pathological processes due to its role in these important cellular functions (35). Although essential for cellular homeostasis, the mechanisms regulating this complex process, and the ramifications of any defects, remain to be fully elucidated. Atg genes control the autophagic process, leading to the induction and nucleation of autophagosomes and their expansion and fusion with lysosomes. Among the Atg genes, Atg1, Atg6 and Atg8 (ULK1, Beclin1 and LC3 in mammals, respectively) are three major regulators of the autophagic pathway (36). In the autophagic pathway, the LC3 protein binds to phosphatidylethanolamine and is recruited to the autophagosome membrane. This lipidated form of LC3 can be detected as a band with an apparently lower molecular weight (LC3II) compared with the non-lipidated, non-autophagic form (LC3I). Therefore, the level of LC3II is an indication of the extent of autophagy (37). In addition, the autophagosomal proteins ULK1 and Beclin1, which initiate autophagy and form autophagosomes, are considered to be markers of the extent of autophagy, as described previously $(38,39)$. Therefore, the mRNA and/or protein expression levels of these three aforementioned markers were measured in the present study. The results showed that the inhibition of ASICla decreased the levels of these autophagy markers, indicating that the inhibition of ASICla suppressed acid-induced autophagy.

ASICla is a proton-gated ion channel for $\mathrm{Ca}^{2+}$ transportation. It is expressed in the mammalian nervous system and other tissues, in which it exerts pathophysiological effects (40). Our previous study indicated the presence of ASICla mRNA and its protein in rat articular chondrocytes (28). In the present study, it was observed that silencing or inhibiting ASICla attenuated the extent of autophagy in rat articular chondrocytes, as indicated by the decreased expression levels of LC3II, ULK1 and Beclin1. This provides further evidence of an association between ASIC1a and autophagy. Previous studies have also confirmed that the activation or sensitization of calcium-permeable ASIC1a is responsible for the acidosis-mediated cellular damage caused by intracellular $\mathrm{Ca}^{2+}$ influx (41). Consistently, in the present study, it was found that silencing or inhibiting ASICla reduced the concentration of intracellular $\mathrm{Ca}^{2+}$, again indicating that increased $\left[\mathrm{Ca}^{2+}\right]_{i}$, mediated via ASIC1a, may contribute to acidosis-induced articular chondrocyte injury.

It is widely accepted that intracellular $\mathrm{Ca}^{2+}$ signaling, as a versatile and dynamic secondary messenger, is essential for important pathophysiological processes in cells. Small changes in $\mathrm{Ca}^{2+}$ can affect the normal physiological cell function. The role of $\mathrm{Ca}^{2+}$ signaling in autophagy has been investigated extensively (42-44). However, the role of $\mathrm{Ca}^{2+}$ signaling in the regulation of autophagy has been a controversial issue, with reports suggesting both inhibitory (45) and stimulatory (43) effects of $\mathrm{Ca}^{2+}$ on autophagy. This discrepancy may be explained by the specific role of different $\mathrm{Ca}^{2+}$ signals; a $\mathrm{Ca}^{2+}$ signal in normal growth-promoting conditions, likely targeted towards mitochondria, inhibits basal autophagy, whereas a different $\mathrm{Ca}^{2+}$ signal under conditions of cellular stress can stimulate autophagy (46). In the present study, BAPTA-AM, a rapid intracellular $\mathrm{Ca}^{2+}$ chelating agent, was used to block $\mathrm{Ca}^{2+}$ channels (47). Consistent with the results of a previous study, which reported that the BAPTA-AM-mediated chelation of intracellular $\mathrm{Ca}^{2+}$ is involved in the regulation of autophagy (48), the results of the present study indicated that the use of BAPTA-AM decreased the activation of autophagy. Of note, when siRNA against ASICla was combined with BAPTA-AM, the expression levels of LC3II, Beclin1 and ULK1 were further reduced. Similar results were also identified in the fluorescence images when the chondrocytes were transfected with the GFP-LC3 plasmid. These results suggest that ASICla and $\mathrm{Ca}^{2+}$ channels may have synergistic roles in affecting the extent of autophagy.

A number of studies have demonstrated that mTOR is a key mediator of growth factor signaling to autophagy $(49,50)$. As the upstream regulatory factors of mTOR, AMPK and $\mathrm{CaMKK} \beta$ are also reported to be involved in the progress of autophagy (25), the CaMKK $\beta / \mathrm{AMPK} / \mathrm{mTOR}$ signaling pathway was evaluated in the present study to examine the mechanisms of ASICla in autophagy. The results showed that downregulated protein levels of $\mathrm{p}-\mathrm{mTOR} / \mathrm{mTOR}$ and upregulated protein levels of $\mathrm{CaMKK} \beta / \beta$-actin and $\mathrm{p}$-AMPK/AMPK were reversed by the inhibition of ASICla, indicating that the 
CaMKK $\beta /$ AMPK/mTOR signaling pathway may be involved in the role of ASICla in autophagy.

The expression levels of LC3-II were significantly decreased in the ASIC1a RNAi and BAPTA-AM groups. The expression of LC3-II was also observed to be decreased further following combined treatment with ASIC1a siRNA and BAPTA-AM in the present study. These results indicated that silencing ASICla and the chelating of $\mathrm{Ca}^{2+}$ by BAPTA-AM inhibited the activation of autophagy induced by acidic stimulation. The mechanism underlying this effect may be as follows: ASICla acts as a cation channel permeable to $\mathrm{Ca}^{2+}$, but other channels also exist that can mediate $\mathrm{Ca}^{2+}$ influx, including transient receptor potential vanilloid channels (51) or store-operated $\mathrm{Ca}^{2+}$ channels (52). By contrast, extracellular acidification stimulation causes an elevation of intracellular $\mathrm{Ca}^{2+}$ concentration, which may involve an influx from extracellular $\mathrm{Ca}^{2+}$ in addition to the release of $\mathrm{Ca}^{2+}$ from an intracellular $\mathrm{Ca}^{2+}$ pool. The concentration of BAPTA-AM used in the present study may have only chelated a proportion of intracellular $\mathrm{Ca}^{2+}$. The combination of BAPTA-AM and ASICla siRNA was more potent than either treatment alone in reducing autophagy. These results suggest that $\mathrm{Ca}^{2+}$ is an important factor in acid-induced autophagy in articular chondrocytes, and ASICla may act as an upstream regulator of autophagy by inhibiting the effects of $\mathrm{Ca}^{2+}$.

In conclusion, the results of the present study confirmed the presence of ASIC1a in articular chondrocyte autophagy in an extracellular acidic environment. As a potential regulator, ASICla induced an increase in intracellular calcium activated by autophagy in acidic cells. In addition, the inhibition of ASICla was found to attenuate the effects of activated autophagy through the $\mathrm{CaMKK} \beta / \mathrm{AMPK} / \mathrm{mTOR}$ signaling pathway, which provides evidence for the involvement of ASIC1 in RA. This suggests that the role of ASICla in chondrocyte autophagy is more complex than originally thought, and may involve crosstalk with other survival strategies. These results provide a basis for further investigation of this potential regulator in chondrocyte autophagy.

\section{Acknowledgements}

Not applicable.

\section{Funding}

This study was supported by the Natural Science Foundation of China (grant no. 81271949).

\section{Availability of data and materials}

All data generated and analyzed during the present study are included in this published article.

\section{Authors' contributions}

WFG, YYX and FHC performed the experiments, contributed to data analysis and wrote the manuscript. WFG, YYX, JFG and FHC analyzed the data. FHC conceptualized the study design and contributed experimental materials. All authors read and approved the final manuscript.

\section{Ethics approval and consent to participate}

All experiments performed on animals were approved by the Animal Ethics Committee and complied with the Principles of Laboratory Animal Use and Care of Animal Ethics Committee of Anhui Medical University (no. LLSC20140039).

\section{Patient consent for publication}

Not applicable.

\section{Competing interests}

The authors declare that they have no competing interests.

\section{References}

1. Scott DL, Wolfe F and Huizinga TW: Rheumatoid arthritis. Lancet 376: 1094-1108, 2010.

2. Malemud CJ: Chondrocyte apoptosis in rheumatoid arthritis: Is preventive therapy possible? Immunotherapy (Los Angel) 1: 102, 2015.

3. Chang J, Wang W, Zhang H, Hu Y, Wang M and Yin Z: The dual role of autophagy in chondrocyte responses in the pathogenesis of articular cartilage degeneration in osteoarthritis. Int J Mol Med 32: 1311-1318, 2013.

4. Waldmann R, Champigny G, Bassilana F, Heurteaux C and Lazdunski M: A proton-gated cation channel involved in acid-sensing. Nature 386: 173-177, 1997.

5. Chen CC, England S, Akopian AN and Wood JN: A sensory neuron-specific, proton-gated ion channel. Proc Natl Acad Sci USA 95: 10240-10245, 1998.

6. Lingueglia E, de Weille JR, Bassilana F, Heurteaux C, Sakai H, Waldmann R and Lazdunski M: A modulatory subunit of acid sensing ion channels in brain and dorsal root ganglion cells. J Biol Chem 272: 29778-29783, 1997.

7. Xiong ZG, Chu XP and Simon RP: $\mathrm{Ca}^{2+}$-permeable acid-sensing ion channels and ischemic brain injury. J Membr Biol 209: 59-68, 2006.

8. Hu W, Chen FH, Yuan FL, Zhang TY, Wu FR, Rong C, Jiang S, Tang J, Zhang CC and Lin MY: Blockade of acid-sensing ion channels protects articular chondrocytes from acid-induced apoptotic injury. Inflamm Res 61: 327-335, 2012.

9. Rong C, Chen FH, Jiang S, Hu W, Wu FR, Chen TY and Yuan FL: Inhibition of acid-sensing ion channels by amiloride protects rat articular chondrocytes from acid-induced apoptosis via a mitochondrial-mediated pathway. Cell Biol Int 36: 635-641, 2012.

10. Yuan FL, Chen FH, Lu WG, Li X, Li JP, Li CW, Xu RS, Wu FR, $\mathrm{Hu} \mathrm{W}$ and Zhang TY: Inhibition of acid-sensing ion channels in articular chondrocytes by amiloride attenuates articular cartilage destruction in rats with adjuvant arthritis. Inflamm Res 59: 939-947, 2010.

11. Martínez-Borra $\mathrm{J}$ and López-Larrea C: Autophagy and self-defense. Adv Exp Med Biol 738: 169-184, 2012.

12. Galluzzi L, Morselli E, Vicencio JM, Kepp O, Joza N, Tajeddine N and Kroemer G: Life, death and burial: Multifaceted impact of autophagy. Biochem Soc Trans 36: 786-790, 2008.

13. He C, Zhu H, Li H, Zou MH and Xie Z: Dissociation of Bcl-2-Beclin1 complex by activated AMPK enhances cardiac autophagy and protects against cardiomyocyte apoptosis in diabetes. Diabetes 62: 1270-1281, 2013.

14. Michaud M, Martins I, Sukkurwala AQ, Adjemian S, Ma Y, Pellegatti P, Shen S, Kepp O, Scoazec M, Mignot G, et al: Autophagy-dependent anticancer immune responses induced by chemotherapeutic agents in mice. Science 334: 1573-1577, 2011.

15. Rubinsztein DC: The roles of intracellular protein-degradation pathways in neurodegeneration. Nature 443: 780-786, 2006.

16. Vural A and Kehrl JH: Autophagy in macrophages: Impacting inflammation and bacterial infection. Scientifica (Cairo) 2014: 825463, 2014

17. Zhou XJ and Zhang H: Autophagy in immunity: Implications in etiology of autoimmune/autoinflammatory diseases. Autophagy 8: 1286-1299, 2012. 
18. Wojtkowiak JW and Gillies RJ: Autophagy on acid. Autophagy 8: 1688-1689, 2012.

19. Caramés B, Hasegawa A, Taniguchi N, Miyaki S, Blanco FJ and Lotz M: Autophagy activation by rapamycin reduces severity of experimental osteoarthritis. Ann Rheum Dis 71: 575-581, 2012.

20. Ureshino RP, Rocha KK, Lopes GS, Bincoletto C and Smaili SS Calcium signaling alterations, oxidative stress, and autophagy in aging. Antioxid Redox Signal 21: 123-137, 2014.

21. Jung $\mathrm{CH}$, Ro SH, Cao J, Otto NM and Kim DH: mTOR regulation of autophagy. FEBS Lett 584: 1287-1295, 2010.

22. Seldin MM, Lei X, Tan SY, Stanson KP, Wei Z and Wong GW: Skeletal muscle-derived myonectin activates the mammalian target of rapamycin (mTOR) pathway to suppress autophagy in liver. J Biol Chem 288: 36073-36082, 2013

23. Wu L, Feng Z, Cui S, Hou K, Tang L, Zhou J, Cai G, Xie Y, Hong Q, Fu B and Chen X: Rapamycin upregulates autophagy by inhibiting the mTOR-ULK1 pathway, resulting in reduced podocyte injury. PLoS One 8: e63799, 2013.

24. Sarkar S, Ravikumar B, Floto RA and Rubinsztein DC: Rapamycin and mTOR-independent autophagy inducers ameliorate toxicity of polyglutamine-expanded huntingtin and related proteinopathies. Cell Death Differ 16: 46-56, 2009.

25. Høyer-Hansen M, Bastholm L, Szyniarowski P, Campanella M, Szabadkai G, Farkas T, Bianchi K, Fehrenbacher N, Elling F, Rizzuto $\mathrm{R}$, et al: Control of macroautophagy by calcium calmodulin-dependent kinase kinase-beta, and Bcl-2. Mol Cell 25: 193-205, 2007.

26. Bohensky J, Leshinsky S, Srinivas V and Shapiro IM: Chondrocyte autophagy is stimulated by HIF-1 dependent AMPK activation and mTOR suppression. Pediatr Nephrol 25: 633-642, 2010.

27. Srinivas V, Bohensky J and Shapiro IM: Autophagy: A new phase in the maturation of growth plate chondrocytes is regulated by HIF, mTOR and AMP kinase. Cells Tissues Organs 189: 88-92, 2009.

28. Yuan FL, Chen FH, Lu WG, Li X, Wu FR, Li JP, Li CW, Wang Y, Zhang TY and Hu W: Acid-sensing ion channel 1a mediates acid-induced increases in intracellular calcium in rat articular chondrocytes. Mol Cell Biochem 340: 153-159, 2010.

29. Xiong ZG, Zhu XM, Chu XP, Minami M, Hey J, Wei WL, MacDonald JF, Wemmie JA, Price MP, Welsh MJ and Simon RP: Neuroprotection in ischemia: Blocking calcium-permeable acid-sensing ion channels. Cell 118: 687-698, 2004.

30. Livak KJ and Schmittgen TD: Analysis of relative gene expression data using real-time quantitative PCR and the 2(-Delta Delta C(T)) method. Methods 25: 402-408, 2001.

31. Mathy-Hartert M, Martin G, Devel P, Deby-Dupont G, Pujol JP, Reginster JY and Henrotin Y: Reactive oxygen species downregulate the expression of pro-inflammatory genes by human chondrocytes. Inflamm Res 52: 111-118, 2003.

32. Razaq S, Wilkins RJ and Urban JP: The effect of extracellular $\mathrm{pH}$ on matrix turnover by cells of the bovine nucleus pulposus. Eur Spine J 12: 341-349, 2003.

33. Mizushima N, Levine B, Cuervo AM and Klionsky DJ: Autophagy fights disease through cellular self-digestion. Nature 451: 1069-1075, 2008.

34. Mariño G, Madeo F and Kroemer G: Autophagy for tissue homeostasis and neuroprotection. Curr Opin Cell Biol 23: 198-206, 2011.

35. Levine B and Kroemer G: Autophagy in the pathogenesis of disease. Cell 132: 27-42, 2008

36. Caramés B, Taniguchi N, Seino D, Blanco FJ, D'Lima D and Lotz M: Mechanical injury suppresses autophagy regulators and pharmacologic activation of autophagy results in chondroprotection. Arthritis Rheum 64: 1182-1192, 2012.

37. Kabeya Y, Mizushima N, Ueno T, Yamamoto A, Kirisako T, Noda T, Kominami E, Ohsumi Y and Yoshimori T: LC3, a mammalian homologue of yeast Apg8p, is localized in autophagosome membranes after processing. EMBO J 19: 5720-5728, 2000.
38. Miki Y, Tanji K, Mori F, Utsumi J, Sasaki H, Kakita A, Takahashi $\mathrm{H}$ and Wakabayashi $\mathrm{K}$ : Alteration of upstream autophagy-related proteins (ULK1, ULK2, Beclin1, VPS34 and AMBRA1) in lewy body disease. Brain Pathol 26: 359-370, 2016

39. Liu W, Shang G, Yang S, Huang J, Xue X, Lin Y, Zheng Y, Wang X, Wang L, Lin R, et al: Electroacupuncture protects against ischemic stroke by reducing autophagosome formation and inhibiting autophagy through the mTORC1-ULK1 complex-Beclin1 pathway. Int J Mol Med 37: 309-318, 2016

40. Pandey AK, Hazari PP, Patnaik R and Mishra AK: The role of ASICla in neuroprotection elicited by quercetin in focal cerebral ischemia. Brain Res 1383: 289-299, 2011.

41. Weng XC, Zheng JQ, Li J and Xiao WB: Underlying mechanism of ASICla involved in acidosis-induced cytotoxicity in rat C6 glioma cells. Acta Pharmacol Sin 28: 1731-1736, 2007.

42. Khan MJ, Rizwan Alam M, Waldeck-Weiermair M, Karsten F, Groschner L, Riederer M, Hallström S, Rockenfeller P, Konya V, Heinemann A, et al: Inhibition of autophagy rescues palmitic acid-induced necroptosis of endothelial cells. J Biol Chem 287: 21110-21120, 2012

43. Wang SH, Shih YL, Ko WC, Wei YH and Shih CM: Cadmium-induced autophagy and apoptosis are mediated by a calcium signaling pathway. Cell Mol Life Sci 65: 3640-3652, 2008.

44. Williams JA, Hou Y, Ni HM and Ding WX: Role of intracellular calcium in proteasome inhibitor-induced endoplasmic reticulum stress, autophagy, and cell death. Pharm Res 30: 2279-2289, 2013.

45. Khan MT and Joseph SK: Role of inositol trisphosphate receptors in autophagy in DT40 cells. J Biol Chem 285: 16912-16920, 2010.

46. Decuypere JP, Bultynck G and Parys JB: A dual role for $\mathrm{Ca}(2+)$ in autophagy regulation. Cell calcium 50: 242-250, 2011.

47. Furuta A, Tanaka M, Omata W, Nagasawa M, Kojima I and Shibata H: Microtubule disruption with BAPTA and dimethyl BAPTA by a calcium chelation-independent mechanism in 3T3-L1 adipocytes. Endocr J 56: 235-243, 2009.

48. Pfisterer SG, Mauthe M, Codogno P and Proikas-Cezanne T: $\mathrm{Ca}^{2+} /$ calmodulin-dependent kinase (CaMK) signaling via CaMKI and AMP-activated protein kinase contributes to the regulation of WIPI-1 at the onset of autophagy. Mol Pharmacol 80: 1066-1075, 2011

49. Khan NM, Ansari MY and Haqqi TM: Sucrose, but not glucose, blocks IL1-beta-induced inflammatory response in human chondrocytes by inducing autophagy via AKT/mTOR pathway. J Cell Biochem 118: 629-639, 2017.

50. Taneike M, Nishida K, Omiya S, Zarrinpashneh E, Misaka T, Kitazume-Taneike R, Austin R, Takaoka M, Yamaguchi O, Gambello MJ, et al: mTOR hyperactivation by ablation of tuberous sclerosis complex 2 in the mouse heart induces cardiac dysfunction with the increased number of small mitochondria mediated through the down-regulation of autophagy. PLoS One 11: e0152628, 2016.

51. Hirata Y and Oku Y: TRP channels are involved in mediating hypercapnic $\mathrm{Ca}^{2+}$ responses in rat glia-rich medullary cultures independent of extracellular pH. Cell Calcium 48: 124-132, 2010.

52. Takahashi K, Yokota $M$ and Ohta T: Molecular mechanism of 2-APB-induced $\mathrm{Ca}(2)(+)$ influx in external acidification in PC12. Exp Cell Res 323: 337-345, 2014.

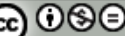

This work is licensed under a Creative Commons Attribution-NonCommercial-NoDerivatives 4.0 International (CC BY-NC-ND 4.0) License. 